\title{
O papel criador do intérprete na efetividade do princípio da dignidade humana
}

\author{
THE CREATIVE ROLE OF THE INTERPRETER IN THE \\ EFFECTIVENESS OF THE PRINCIPLE OF HUMAN \\ DIGNITY
}

\section{Bernardo Schimidt Penna*}

Resumo: Dignidade da pessoa humana, como conceituá-la? Cecília Meirelles definiu, de maneira poética, o vocábulo liberdade: "Essa palavra que o sonho humano alimenta. Que não há ninguém que explique e ninguém que não entenda". Destarte, pode-se, por analogia, transportar os belos versos para o Direito, e, dessa forma, referir-se à dignidade humana. Realmente, não é tarefa simples definir dignidade, pois seus contornos são, propositadamente, imprecisos e vagos. Nesse sentido, este artigo expõe um estudo da dignidade humana como princípio e em seus aspectos filosóficos e jurídicos, levando ainda em conta a participação do Legislativo, do Judiciário e da própria sociedade para a sua concretização e efetivação, a fim de se chegar a uma análise ao menos razoável desse valor, e, assim, compreender a função do intérprete diante da perspectiva de sua atividade criativa e criadora.

Palavras-chave: Direito; Estado; Fundamento; Dignidade; Interpretação.

Abstract: Human dignity, how to define it? Cecilia Meirelles defined the word freedom in a poetic way: "This word that the human dream feeds. Which no one can explain and that there is no one who does not understand". Thus, by analogy, we can carry the beautiful verses to Law and refer to human dignity. Indeed, defining dignity is not a simple task, because its outlines are purposely vague and imprecise. Thus, this paper presents a study of human dignity as a principle and its philosophical and legal aspects, taking also into account the participation of the legislature, the judiciary and society itself for its implementation and enforcement in order to reach an, at least reasonable, analysis of this value, and, so, understanding the role of the interpreter at the prospect of his creative activity.

* Faculdades Integradas de Cacoal (UNESC), Mestre em Direito UNICOR; advogado; professor universitário. email: bernardo@unescnet.br 


\section{INTRODUÇÃO}

Cecília Meirelles (2008, p. 66) definiu, de maneira poética, o vocábulo liberdade: "Essa palavra que o sonho humano alimenta. Que não há ninguém que explique e ninguém que não entenda". Pode-se, por analogia, transportar os belos versos para o Direito e, dessa forma, referir-se à dignidade humana. Realmente, não é tarefa simples definir dignidade. Mas, certamente, se saberá seu significado, pelo menos empiricamente.

A definição do dicionário Aurélio que traz a dignidade como "nobreza, respeitabilidade ou respeito que merece alguém ou alguma coisa" é insuficiente, sobretudo em se tratando de perquirição científica.

A própria doutrina jurídica entende que se chegar a uma definição clara do que seja real e efetivamente a dignidade humana não parece ser possível, já que seus contornos são, propositadamente, imprecisos e vagos.

Para que se chegue a uma análise ao menos razoável desse valor, é necessária uma avaliação mais profunda e mais abrangente. Pretende-se no presente artigo expor um estudo da dignidade humana como princípio e em seus aspectos filosóficos e jurídicos, levando ainda em conta a participação do Legislativo, do Judiciário e da própria sociedade para sua concretização e efetivação.

A função primordial do intérprete em sua efetivação será o objeto principal do presente estudo, buscando-se apontar a sua real função, sobretudo diante da perspectiva de sua atividade criativa e criadora. Não se pretende, nessas poucas páginas, esgotar um tema tão amplo, sendo apenas objetivo traçar alguns parâmetros a título de contribuição para um melhor entendimento.

\section{PRINCÍPIO JURÍDICO E A DIGNIDADE HUMANA COMO PRINCÍPIO}

O princípio fundamental da dignidade humana pode ser hoje considerado a mola mestra, vetor e fim do ordenamento jurídico, não só brasileiro, como da maioria dos Estados. É, em nome de sua proteção, promoção e desenvolvimento que se guia o direito moderno.

Sarlet (2004, p. 110-1), em seus estudos, afirma que:

Com o reconhecimento expresso, no título dos princípios fundamentais, da dignidade da pessoa humana como um dos fundamentos do nosso Estado 
democrático (e social) de Direito, o constituinte de 1987/88, além de ter tomado uma decisão fundamental a respeito do sentido, da finalidade e da justificação do exercício do poder estatal e do próprio Estado, reconheceu expressamente que é o Estado que existe em função da pessoa humana, e não o contrário, já que o homem constitui a finalidade precípua, e não meio da atividade estatal.

Segundo Alexy (2001), princípios são mandados de otimização. Com isso, os princípios como ordem que devem ser, ao máximo, aplicadas; devem permear o ordenamento. Quanto mais for possível a sua aplicação, melhor. No escólio de Larenz (1997), o princípio deve ser entendido como uma pauta aberta, carecida de concretização, e que torna a valoração jurídica explícita, sendo o modo mais apropriado de refleti-la.

Canotilho (2003,p. 1.255) entende os princípios como "normas que exigem a realização de algo, da melhor forma possível, de acordo com as possibilidades fáticas e jurídicas".

Conforme Ávila (2006, p. 72), os princípios “são normas-do-que-deveser: seu conteúdo diz respeito a um estado ideal de coisas”. E conceitua:

Os princípios são normas imediatamente finalísticas, primariamente prospectivas e com pretensão de complementariedade e de parcialidade, para cuja aplicação se demanda uma avaliação da correlação entre o estado de coisas a ser promovido e os efeitos decorrentes da conduta havida como necessária à sua promoção (ÁVILA, 2006, p. 78-9).

Já se tornou clássica a lição de Bandeira de Mello (2003, p. 104) acerca da diferença de repercussão em termos da violação de uma regra ou de um princípio, que, no caso dos últimos, terão impacto negativo em todo o ordenamento, haja vista seu enorme grau de generalidade. Segundo o autor:

Violar um princípio é muito mais grave que transgredir uma norma. A desatenção ao princípio implica ofensa não apenas a um específico mandamento obrigatório, mas a todo o sistema de comandos. É a mais grave forma de ilegalidade ou inconstitucionalidade, conforme o escalão do princípio violado, porque representa insurgência contra todo o sistema, subversão de seus valores fundamentais, contumélia irremissível a seu arcabouço lógico e corrosão de sua estrutura mestra (BANDEIRA DE MELLO, 2003, p. 104). 
A dignidade humana como princípio pode ser considerada verdadeira cláusula geral em nosso ordenamento. "É característico para a cláusula geral o ela estar carecida de preenchimento com valorações, isto é, o ela não dar os critérios necessários para a sua concretização" (CANARIS, 2002, 142).

Martins-Costa (2000, p. 303) conceitua a cláusula geral como:

Uma disposição normativa que utiliza, no seu enunciado, uma linguagem de tessitura intencionalmente abeta, fluida ou vaga, caracterizando-se pela ampla extensão do seu campo semântico, a qual é dirigida ao juiz de modo a conferirlhe um mandato para que, à vista dos casos concretos, crie, complemente ou desenvolva normas jurídicas, mediante reenvio para elementos cuja concretização pode estar fora do sistema.

No mesmo sentido, propugna Perlingieri (2008, p. 37), referindo-se à dignidade humana, que:

É necessário que, com força, a questão moral, entendida como um efetivo respeito à dignidade da vida de cada homem e, portanto, como superioridade deste valor relativamente a qualquer razão política da organização da vida em comum, seja recolocada no centro do debate na doutrina e no foro, como única indicação idônea a impedir a vitória de um direito sem justiça.

Com efeito, nota-se que a dignidade é multifacetária e carece de uma construção sistemática e permanente.

\section{A DIGNIDADE EM SEUS ASPECTOS FILOSÓFICO E JURÍDICO}

É possível ainda se analisar a dignidade humana sobre prismas diversos, como o seu aspecto filosófico e jurídico, que não se confundem, mas se complementam.

\subsection{O aspecto filosófico}

A expressão “dignidade humana” é aberta, fluida, plástica. Sugere, para tanto, uma análise ampla do instituto, num primeiro momento sob o prisma filosófico. Conforme Sarlet (2004, p. 111), segundo a filosofia estoica, "a dignidade 
era tida como a qualidade que, por ser inerente ao ser humano, o distinguia das demais criaturas."

Partindo-se desse prisma, chegou-se à visão cristã, expressa por São Tomás, em que a dignidade era enxergada com duplo caráter: inerente ao homem como espécie e em sua alma, fazendo com que não se volte apenas para Deus, mas também para si mesmo.

Os jusnaturalistas dos séculos XVII e XVIII fizeram com que a dignidade humana passasse por um processo de racionalização e laicização, mas mantendo sua noção fundamental (SARLET, 2004, p. 112), passando, depois, pelos iluministas, com destaque para Kant e seu "imperativo categórico", voltado para um comportamento humano em que a vontade possa sempre valer como um princípio para uma legislação geral. Para Kant, coisas têm preço e pessoas têm dignidade (MORAES, 2010, p. 76).

\section{$2.2 \mathrm{O}$ aspecto jurídico}

Moraes (2010, p. 82) apresenta um viés jurídico para a questão, citando Antônio Junqueira de Azevedo, que entende a dignidade humana "baseada nos seguintes preceitos: respeito à integridade física e psíquica das pessoas; consideração pelos pressupostos materiais mínimos para o exercício da vida e o respeito pelas condições mínimas de liberdade e convivência social igualitária".

A dignidade humana permeia todo o arcabouço jurídico. Segundo ela, por análise inversa, “será 'desumano' tudo aquilo que puder reduzir a pessoa à condição de objeto" (MORAES, 2010, p. 85). Segundo a autora (id., ibid., p. 85), o substrato material da dignidade humana pode ser desdobrado em quatro postulados: "o sujeito moral reconhece a existência dos outros como sujeitos iguais a ele; merecedores do mesmo respeito à integridade psicofísica; dotado de vontade livre e parte do grupo social." Tais postulados se refletirão, respectivamente, nos princípios da igualdade, da integridade física e moral, da liberdade e da solidariedade.

Barroso (2012) entende que:

A dignidade da pessoa humana vem inscrita na Constituição brasileira como um dos fundamentos da república. Funciona, assim, como um fator de legitimação das ações estatais e vetor de interpretação da legislação em geral. (...) No mundo contemporâneo, a dignidade humana tornou-se o centro 
axiológico dos sistemas jurídicos, a fonte dos direitos materialmente fundamentais, o núcleo essencial de cada um deles.

Para Canotilho (2003, p. 225), a dignidade da pessoa humana como base da república significa "o reconhecimento do indivíduo como limite e fundamento do domínio político da república".

Sarlet (2004, p. 114) aduz que:

A dignidade humana é qualidade intrínseca da pessoa humana, algo que simplesmente existe, sendo irrenunciável e inalienável, na medida em que constitui elemento que qualifica o ser humano como tal e dele não pode ser destacado, de tal sorte que não se pode cogitar na possibilidade de determinada pessoa ser titular de uma pretensão a que lhe seja concedida a dignidade.

No ordenamento brasileiro, a dignidade humana tem status constitucional, figurando como fundamento da República, insculpido no art. $1 .^{\circ}$, inciso III:

Art. 1. ${ }^{\circ}$ A República Federativa do Brasil, formada pela união indissolúvel dos Estados e Municípios e do Distrito Federal, constitui-se em Estado Democrático de Direito e tem como fundamentos:

$[\ldots]$

III - a dignidade da pessoa humana.

Segundo Perlingieri (2008, p. 205), “o caráter fundamental se identifica por meio da constitucionalidade: os princípios constitucionais, explicitamente expressos ou declarados mediante referências explícitas, são os fundamentos de um sistema concebido hierarquicamente".

\section{DIGNIDADE POR AUTONOMIA E POR HETERONOMIA}

Barroso (2012), numa outra perspectiva, encontra uma dupla visão da dignidade, ligada à aplicabilidade prática, dividindo-a em dignidade por autonomia (condição interna ao indivíduo) e por heteronomia (produto de uma atuação externa a ele). Conclui que "a concepção da dignidade como autonomia valoriza o indivíduo, suas liberdades e seus direitos fundamentais. A dignidade como heteronomia, por sua vez, funciona como uma limitação à liberdade individual, pela imposição de valores sociais e pelo cerceamento de condutas 
próprias que possam comprometer a dignidade do indivíduo (BARROSO, 2012). Afirma, ainda, que na Constituição brasileira a dignidade se manifesta predominantemente sob a forma de autonomia.

Em sede internacional, tem-se também que, como dispõe a Declaração Universal da ONU, assim como a doutrina majoritária, a dignidade da pessoa humana reside principalmente na autonomia e no direito de autodeterminação da pessoa (SARLET, 2004, p. 115).

Diante disso, tem-se que a dignidade é exercida pelo próprio sujeito, mas, para tanto, é necessária sua efetiva promoção e proteção pelo Estado, e, pelo menos, um caminho que, concretamente, ainda não se vislumbra no ordenamento brasileiro. Com isso, ganha força a importância do intérprete.

\section{A PARTICIPAÇÃO DO INTÉRPRETE NA EFETIVIDADE DO PRINCÍPIO DA DIGNIDADE HUMANA}

O princípio da dignidade humana é cláusula geral, aberta, elástica, adaptável ao caso concreto, não devendo ser concebida de maneira enumerativa, e sim como valor, sem limitações injustificáveis, sobreposto aos demais princípios, para que seu fim seja efetivamente alcançado.

Sua concretização, entendida no presente estudo como a existência de uma normatividade, depende fundamentalmente do legislador. No entanto, na ausência de uma normatividade ao menos razoável, não se pode ficar à espera. Caberá ao judiciário a sua efetividade.

Efetividade, segundo Wolkmer (1994, p. 86), é “[...] critério ou modo de aplicação real de certas medidas que permite solucionar as prioridades e os objetivos essenciais reclamados por uma sociedade". Essa essencialidade é própria do princípio da dignidade humana, já que se demonstra como um princípio solar do ordenamento.

\subsection{O estímulo doutrinário à decisão criadora}

A efetividade do princípio da dignidade humana reclama uma análise acurada do caso concreto, com suas particularidades, levando o juiz a criar, a inovar quando necessário.

Derrida (2007, p. 44) comenta sobre o que chama de julgamento inaugural, ato de interpretação reinstaurador: 
O novo frescor, o caráter inicial desse julgamento inaugural pode repetir algo, ou melhor, deve ser conforme a uma lei preexistente, mas a interpretação reinstauradora, reinventiva e livremente decisória do juiz responsável, requer que sua "justiça" não consista apenas na conformidade, na atividade conservadora e reprodutora de seu julgamento. Em suma, para que uma decisão seja justa e responsável é preciso que, em seu momento próprio, se houver um, ela seja ao mesmo tempo regrada e sem regra, conservadora da lei ou suficientemente destruidora ou suspensiva da lei para dever reinventála em cada caso, rejustificá-la, reinventá-la pelo menos na reafirmação e na confirmação nova e livre de seu princípio.

Para Haberle (1997, p. 80), “a interpretação é um processo aberto. Não é, pois, um processo de passiva submissão, nem se confunde com a recepção de uma ordem. A interpretação conhece possibilidades e alternativas diversas".

Deve-se, no entanto, haver um respeito não só à hierarquia das fontes, já que a proteção à dignidade humana tem assento constitucional, mas também à hierarquia dos valores, por se posicionar como valor fundamental em nosso ordenamento.

O respeito hierárquico à Constituição, com norma maior, não se encontra apenas no respeito às técnicas de produção normativa, mas na necessidade de que o conteúdo da norma esteja de acordo com os valores presentes na própria constituição (PERLINGIERI, 2008, p. 324). A decisão judicial no caso concreto também se submete a essa análise.

O formalismo e o positivismo constituem o grande lastro metodológico do século vinte (CORDEIRO apud CANARIS, 2002, p. XVI). No entanto, o desapego à ditadura das regras, próprio de doutrinas modernas, como o póspositivismo, serve como importante método para uma melhor interpretação e aplicação em meio escala do princípio, que, afinal, é defendida pela aludida escola. Perlingieri chama de "passagem do primado da lei ao primado do direito" (CORDEIRO apud CANARIS, 2002, p. 54).

No entanto, mesmo teorias dogmáticas já se inclinam para uma possibilidade de interpretação construtiva. Luhmann (apud LARENZ, 1997, p. 321-4), defende a dogmática entendendo possível - e própria - uma responsabilidade e mesmo uma segurança criativa, nestes termos:

A função positiva da dogmática poderia consistir em que, por via do modo do arranjo das interdições de negação, se eleva ao nível requerido a 
flexibilidade na interpretação de textos e experiências. Para o jurista atual, o sentido da dogmática não consiste em fixar o que está simplesmente estabelecido, mas em possibilitar a distância crítica, em organizar estratos de reflexões, de motivos, de ponderações de proporção. [...] a justiça referese às exigências gerais do Direito; a dogmática representa o plano imanente ao sistema jurídico, no qual estas exigências se reespecificam e operacionalizam.

Mesmo outras teorias também sustentam a possibilidade criadora do intérprete, posto tímida, ainda presas a algo positivo, como a Pandectística, com Windscheid, a "Jurisprudência dos interesses", com Heck, a "Jurisprudência dos valores” (ENGISCH, 2001, p. 171), e, mais livremente, ampliando um pouco a participação do intérprete por meio do pensamento voltado aos problemas, a “Tópica” (VIEHWEG, 2006).

Medina (2011, p. 76-7) reforça ao dizer que, "na medida em que tenham que fazer escolhas, portanto, exercem os magistrados uma atividade criativa. A criação do direito, iniciada pelo legislador, só se completa em juízo". Para Haberle (1997, p. 30) a nova hermenêutica consegue contrariar a lógica da subsunção. Engisch (2001, p. 207) defende que:

As leis são hoje, em todos os domínios jurídicos, elaboradas por tal forma que os juízes não descobrem e fundamentam suas decisões tão-somente através da subsunção a conceitos jurídicos fixos, a conceitos cujo conteúdo seja explicitado com segurança através da interpretação, mas antes são chamados a valorar autonomamente e, por vezes, a decidir e a agir de um modo semelhante ao do legislador.

Perlingieri (2008, p. 75) cita Camerte para consignar que "não existe um único método jurídico, mas uma metodologia jurídica feita de pluralidade, de possíveis métodos de pesquisa, frequentemente concorrentes e complementares."

Dworkin (1999, p. 110-1) pondera que:

A dinâmica da interpretação resiste à convergência ao mesmo tempo que a promove, e as forças centrífugas são particularmente fortes ali onde as comunidades profissional e leiga se dividem com relação à justiça. Juízes diferentes pertencem a tradições políticas diferentes e antagônicas, e a lâmina das interpretações de diferentes juízes será afiada por diferentes ideologias. 
Ainda com Perlingieri (2008, p. 222-3), tem-se que:

A teoria da interpretação, mais do que técnica voltada a esclarecer os significados de normas bem individuadas, assume, em um ordenamento complexo e aberto, a função mais delicada de individuar a normativa a ser aplicada ao caso concreto, combinando e coligando disposições, as mais variadas, mesmo de nível e proveniência diversos, para conseguir extrair do caos legislativo a solução mais congruente, respeitando os valores considerados normativamente prevalecentes assim como os cânones da equidade, proporcionalidade e razoabilidade.

Todavia, a teoria mais moderna de apoio ao poder criativo do intérprete é o pós-positivismo, que para Barroso (2003, p. 291) significa:

A designação provisória e genérica de um ideário difuso, no qual se incluem a definição das relações entre valores, princípios e regras, aspectos da chamada nova hermenêutica constitucional, e a teoria dos direitos fundamentais, edificada sob o fundamento da dignidade da pessoa humana.

Bonavides (2003, p. 264), ao analisar o pós-positivismo, afirma que "as constituições promulgadas [no século XX] acentuam a hegemonia axiológica dos princípios, convertidos em pedestal normativo sobre o qual assenta todo o edifício jurídico dos novos sistemas constitucionais".

Coelho (2003, p. 81-2) cita a divisão entre os interpretativistas e os não-interpretativistas. Os primeiros consideram incompatível com o princípio democrático qualquer criatividade judicial forte. Para eles, "interpretar é simplesmente aplicar a norma com o sentido e o alcance que lhe atribuíram as instâncias de representação popular, cujas decisões políticas não podem ser substituídas por decisões jurídicas".

Os não-interpretativistas, por seu turno, são os que consideram legítima a invocação de outros valores substantivos. Levam em conta a historicidade e a estrutura do texto constitucional, formado essencialmente por princípios, com enunciados abertos e que só adquirem efetividade com a mediação dos aplicadores (COELHO, 2003, p. 83).

Na lição de Ávila (2006, p. 32-3), o intérprete não deve meramente descrever o significado previamente existente dos dispositivos; nem se deve 
aceitar a ideia de uma atividade de subsunção entre conceitos prontos. "O intérprete não só constrói, mas reconstrói sentido".

Os juristas, para Perlingieri (2008, p. 609), "se não são copiadores e repetidores, são autores que, alcançando o princípio do direito e trabalhando em torno das fontes do direito, garantem a adequação daquilo que é interpretado."

Como o presente estudo pretende demonstrar a importância da função do intérprete na efetividade do princípio da dignidade humana, insta mencionar a lição de Ávila quanto ao que ele chama de eficácia seletiva dos princípios, "que se baseia na constatação de que o intérprete não trabalha com fatos brutos, mas construídos. Os fatos são construídos pela mediação do discurso do intérprete" (2006, p. 100). E, por terem matiz constitucional, Coelho (2003, p. 91) invoca uma interpretação especificamente constitucional, que vem a ser a interpretação com um entre os resultados possíveis e jamais definitivos, já que o texto constitucional permanece aberto e receptivo a novas leituras.

Medina (2011, p. 34) afirma que "a Constituição é, em boa medida, capaz de transformar a realidade a ela subjacente". Porém, conclui que "a Constituição não conseguirá dominar, de imediato, todos os elementos da realidade. No entanto, a sua força normativa há de ser exercitada continuamente, a fim de alcançar, com o tempo, cada vez maior efeito" (id., ibid., p. 41).

Ainda com Medina (2011, p. 94) tem-se que "será por intermédio da argumentação que os fatores sociais haverão de ser empregados na determinação do sentido atual das normas jurídicas, após terem sido recolhidos pelo julgador que se animar a olhar para fora da Constituição, em busca do significado do documento".

\subsection{Limites do poder criador do intérprete}

É necessário prudência quando de sua aplicação, já que o afastamento da dogmática e do positivismo não pode significar um alargamento sem limites do poder do intérprete.

Medina (2011, p. 76-7) consigna que: 
Há, com efeito, limites à criatividade judicial. A exigência de que as determinações dos representantes do povo prevaleçam na disciplina da vida em sociedade não se coaduna com a possibilidade de os juízes decidirem com total liberdade. É que as sentenças não se legitimam quando não apresentam argumentos hábeis a demonstrar que o seu comando apóia-se em uma interpretação - mesmo que controvertida - do direito vigente.

O juiz não deve julgar conforme sua consciência, e sim conforme o ordenamento jurídico, sobretudo a Constituição e seus fundamentos. É essa, em síntese, a crítica que faz Streck (2010), ao afirmar que as decisões judiciais não devem ser tomadas a partir de critérios pessoais, e que, na democracia, não cabe mais dizer que entre a lei é a consciência, pois se opta pelo sentimento do justo.

A consciência do sujeito não contempla apenas valores positivos. É nela, também, que se encontram seus preconceitos, traumas, crenças etc. O alargamento do poder do juiz visando à construção do Direito e à justiça substancial, desiderato do pós-positivismo, é salutar, porém deve ser atingido sempre com a devida parcimônia e com sólida estrutura argumentativa.

Moraes (2010, p. 16) ressalta que "a aceitação racional das decisões judiciais deve ser guiada pela qualidade dos argumentos levantados e que a chamada 'constitucionalização' não pode funcionar como um pretexto a conferir ao magistrado carta branca para decidir conforme suas convicções pessoais".

Conforme Atienza (2003, p. 22), a teoria padrão da argumentação jurídica se situa no contexto de justificação dos argumentos. O autor exemplifica, ao se referir à razão justificadora da decisão, que:

Dizer que o juiz tomou a decisão devido às suas fortes crenças religiosas significa enunciar uma razão explicativa; dizer que a decisão do juiz se baseou numa determinada interpretação de um dispositivo normativo significa enunciar uma razão justificadora. De modo geral os órgãos jurisdicionados ou administrativos não precisam explicar suas decisões; o que devem fazer é justificá-las (ATIENZA, 2003, p. 22).

O intérprete cria Direito por meio de uma interpretação, que consiste em um ato de vontade em que o órgão aplicador escolhe uma entre várias 
possibilidades, estando, entretanto, vinculado a textos de direito, especialmente os que veiculam princípios. A fluidez, a plasticidade dos textos não é absoluta (GRAU, 2005, p. 208-9).

\section{CONSIDERAÇÕES FINAIS}

Kriele (apud LARENZ, 1997, p. 207) opina que "uma decisão encontra-se, porém, justificada e, nestes termos, também a do legislador, como em última instância também a do juiz, quando confere prevalência àquele interesse que é inequivocamente fundamental no concerto dos interesses gerais em jogo".

Conclui-se, primeiramente, com a lição de Daniel Sarmento, que "o princípio da dignidade humana representa o epicentro da ordem constitucional, irradiando efeitos sobre todo o ordenamento jurídico. (...) É o que confere unidade de sentido e valor a sistema constitucional, que repousa da ideia de respeito irrestrito ao ser humano - razão última do Direito e do Estado (SARMENTO, 2002).

Perlingieri (2008, p. 37) também salienta que:

É necessário que, com força, a questão moral, entendida como um efetivo respeito à dignidade da vida de cada homem e, portanto, como superioridade deste valor relativamente a qualquer razão política da organização da vida em comum, seja recolocado no centro do debate na doutrina e no foro, como única indicação idônea a impedir a vitória de um direito sem justiça.

Para Sarlet (2004, p. 120), não restam dúvidas de que toda a atividade estatal está vinculada ao respeito ao princípio da dignidade humana, sendolhe imposto um dever de respeito e proteção, tanto se abstendo de ingerências nocivas na esfera individual, quanto no dever de protegê-las contra agressões de terceiros.

Haberle (apud BONAVIDES, 2003, p. 597) invoca que a efetividade dos direitos fundamentais não é automática nem espontânea, prendendo-se a uma pluralidade de intérpretes, sendo o resultado complexo e cheio de riscos de processos particularizados de interpretação, com vários participantes, incluindo os destinatários e os titulares desses direitos. 
Por fim, Hesse (apud MEDINA, 2011, p. 94), embora chame de concretização o que no presente estudo tem-se chamado de efetividade, ensina que é precisamente onde o conteúdo constitucional não se mostra claro que a interpretação assume o caráter de uma atividade criativa.

\section{REFERÊNCIAS}

ALEXY, Robert. Teoria da Argumentação Jurídica. Tradução Zilda Hutchinson Silva. São Paulo: Landy, 2001.

ATIENZA, Manuel. As Razões do Direito: Teorias da Argumentação jurídica. 3. ed. São Paulo: Landy, 2003.

ÁVILA, Humberto. Teoria dos Princípios: da definição à aplicação dos princípios jurídicos. 5. ed. São Paulo: Malheiros, 2006.

BARROSO, Luís Roberto. O direito constitucional e a efetividade de suas normas: limites e possibilidades da Constituição brasileira. 7. ed. Rio de Janeiro: Renovar, 2003.

et al. $\boldsymbol{A}$ Morte como ela é: dignidade e autonomia individual no fim da vida. Disponível em: $<w w w . l u i s r o b e r t o b a r r o s o . c o m . b r>$. Acesso em: 15 mar. 2012.

BONAVIDES, Paulo. Curso de Direito Constitucional. 13. ed. São Paulo: Malheiros, 2003.

CANARIS, Claus Wilhem. Pensamento Sistemático e Conceito de Sistema na Ciência do Direito. Tradução A. Menezes Cordeiro. 3. ed. Lisboa: Calouste Gulbenkian, 2002

CANOTILHO, José Joaquim Gomes. Direito Constitucional e Teoria da Constituição. 7. ed. Lisboa: Almedina, 2003.

COELHO, Inocêncio Mártires. Interpretação Constitucional. 2. ed. Porto Alegre: Safe, 2003. 
DERRIDA, Jacques. Força de Lei. São Paulo: Martins Fontes, 2007.

DWORKIN, Ronald. O império do direito. Tradução Jefferson Luiz Camargo. São Paulo: Martins Fontes, 1999.

ENGISCH, Karl. Introdução ao Pensamento Jurídico. Tradução J. Batista Machado. 8. ed. Lisboa: Calouste Gulbenkian, 2001.

GRAU, Eros Roberto. O Direito Posto e o Direito Pressuposto. 6. ed. São Paulo: Malheiros, 2005.

HABERLE, Peter. Hermenêutica Constitucional. Tradução Gilmar Ferreira Mendes. Porto Alegre: Safe, 1997.

LARENZ, Karl. Metodologia da Ciência do Direito. 3. ed. Tradução José Lamego. Lisboa: Calouste Gulbenkian, 1997.

MARTINS-COSTA, Judith. A Boa-fé no Direito Privado. São Paulo: Revista dos Tribunais, 2000.

MEDINA, Marcelo Borges de Mattos. Constituição e Realidade: a Influência das transformações sociais na jurisdição constitucional. Rio de Janeiro: Renovar, 2011.

MEIRELLES, Cecília. Romanceiro da Inconfidência. Porto Alegre: L\&PM, 2008.

MELLO, Celso Antônio Bandeira de. Curso de Direito Administrativo. 15. ed. São Paulo: Malheiros, 2003.

MORAES, Maria Celina Bodin de. Na Medida da Pessoa Humana. Rio de Janeiro: Renovar, 2010.

PERLINGIERI, Pietro. O Direito Civil na Legalidade Constitucional. Tradução Maria Cristina de Cicco. Rio de Janeiro: Renovar, 2008. 
STRECK, Lênio Luis. $O$ que é isto: Decido conforme minha consciência? Porto Alegre: Livraria do Advogado, 2010.

VIEHWEG, Theodor. Tópica e Jurisprudência. Tradução Kelly Alfen da Silva. São Paulo: Safe, 2006.

WOLKMER, Antônio Carlos. O Terceiro Mundo e a Nova Ordem Internacional. 2. ed. São Paulo: Ática, 1994.

Artigo recebido em: 26/08/2013 Aprovado para publicação em: 30/06/2014

Como citar: PENNA, Bernardo Schimidt. O papel criador do intérprete na efetividade do princípio da dignidade humana. Scientia Iuris, Londrina, v.18, n.1, p.241-256, jul.2014. DOI: 10.5433/2178-8189.2014v18n1p241. 